$\mathrm{Oz}$

$1-1-2006$

\title{
Vacillations Between Discrete and Ecological Thinking: The University of Arkansas Community Design Center
}

Stephen Luoni

Follow this and additional works at: https://newprairiepress.org/oz

(c) $($ ) $\Theta \Theta$

This work is licensed under a Creative Commons Attribution-Noncommercial-No Derivative Works 4.0 License.

\section{Recommended Citation}

Luoni, Stephen (2006) "Vacillations Between Discrete and Ecological Thinking: The University of Arkansas Community Design Center," Oz: Vol. 28. https://doi.org/10.4148/2378-5853.1433

This Article is brought to you for free and open access by New Prairie Press. It has been accepted for inclusion in Oz by an authorized administrator of New Prairie Press. For more information, please contact cads@k-state.edu. 


\section{Vacillations Between Discrete and Ecological Thinking}

The University of Arkansas Community Design Center

\section{Stephen Luoni}

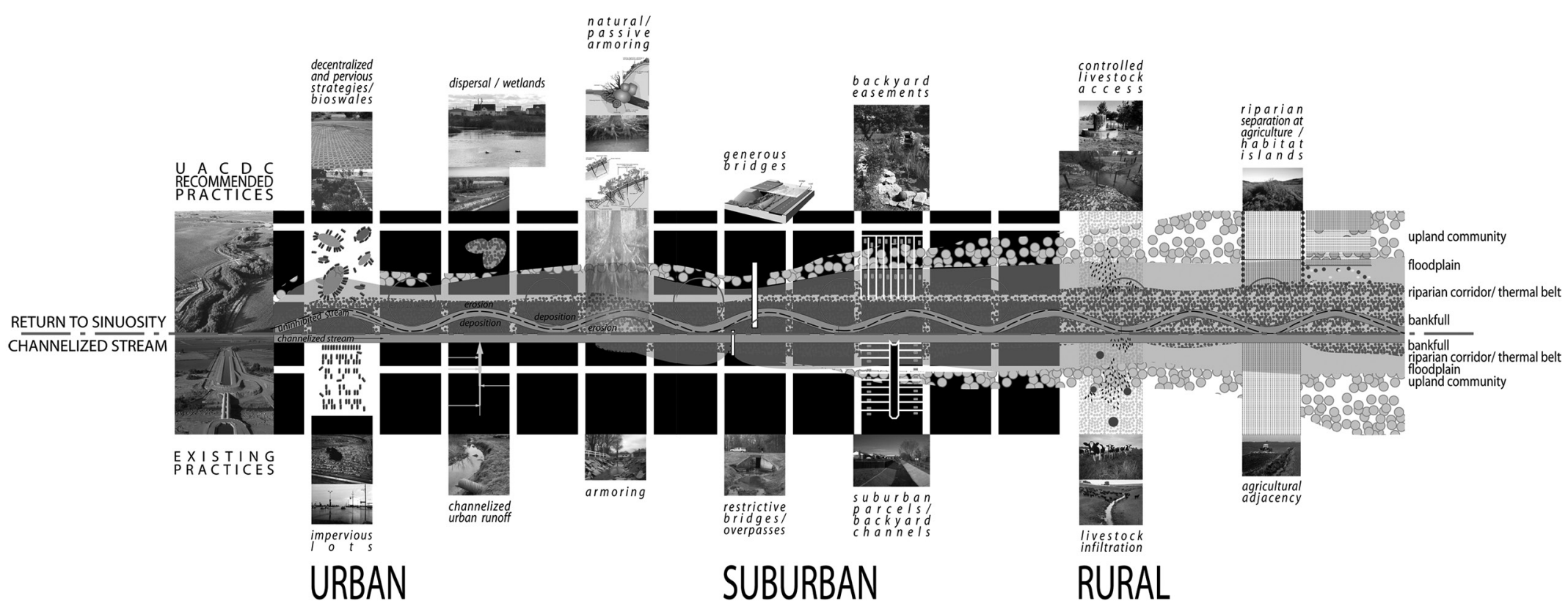

\section{Working Upstream}

How odd is it to devote an anthology of essays to humanitarian design? Isn't it an oxymoron given the design professions' tacit mission to provide human habitat? After all, professions are cultures of work distinguished by their internalization of the public good in the delivery of services and products. Unlike the vocational and commercial service sectors, professions like medicine, teaching, law, and design integrate the market objectives of practice with non-market obligations to the public. Perhaps the theme strategically indicates-or manifests-larger fissures in professional discourse. How much architectural project bear, and are there services beyond the project (e.g., planning, public policy, infrastructure development, housing production, project delivery systems) by which the public welfare is mainstreamed? While service to underserved populations is certainly an imperative, it remains little more than scattered pro bono activity contingent upon market excesses in the design professions. Such service usually results in downstream solutions, designed to ease distress, leaving little energy to form proactive positions. Too often, humanitarianism in design slips into sentimentality or congratulations retarding opportunity for tactical thinking. Instead, let's redirect the inquiry away from the subject of surplus toward one of centrality in larger socio-environmental forces-the core intention of the humanities as a field of thought. This begins with ecological thinking...the notion that everything is connected to everything else.

Architecture is still a profession of discrete practices. Unlike medicine's institutionalization of public health platforms through teaching hospitals research institutes, and other non-governmental organizations, the design professions lack an institutionalized public service culture beyond university schooling. Arguably, the public itself is the underserved constituent when it comes to design of the environment To be sure, there are agenda-setting organizations like the Congress for New Urbanism and the Urban Land Institute, effective in their efforts to revise land use and development codes toward more creative ends. There is The Mayors' Institute on City Design's work with select communities to centralize the role of design in municipal governance. A handful of universities house struggling community design centers, while a few chapters of the American Institute of Architects, like the Boston Society of Architects, sponsor meaningful education and research initiatives. Yet these important efforts linking policy, governance, and design 


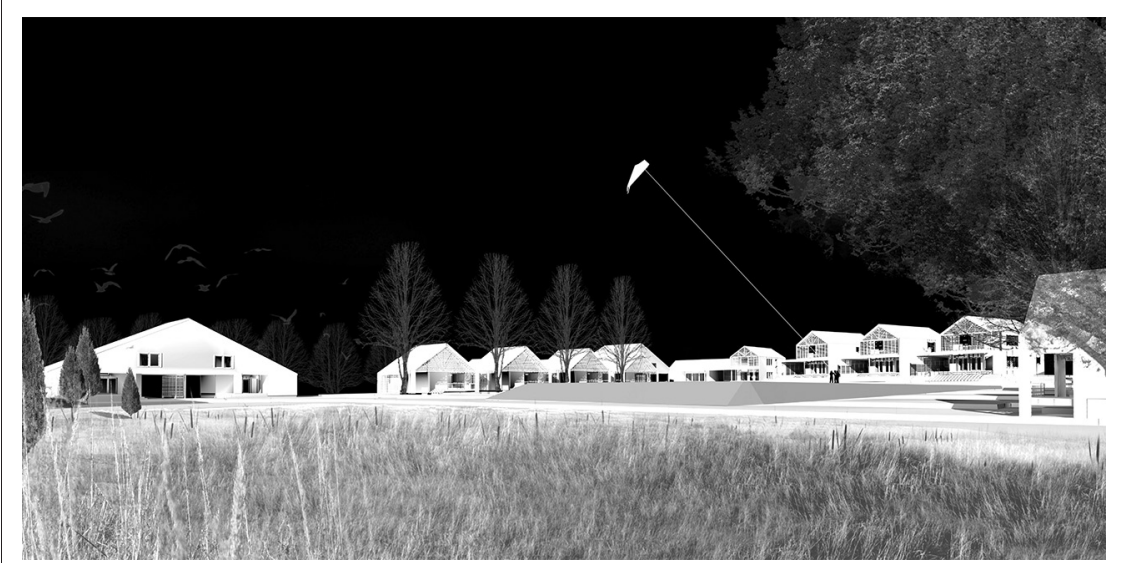

have not been mainstreamed in design's education and practice infrastructures (wouldn't post-Katrina governance require this?). Similar to public health's embedded constituency, how might design solve for a public beyond the residue of charitable service? This involves the renewal of disciplinary traditions that amplify the sustainability, livability, and urbanity in our shared environments.

\section{Solving for Pattern: \\ Development of}

Place-Based Models

The mission of the University of Arkansas Community Design Center (UACDC) is to advance creative development in Arkansas through education, research, and design solutions that enhance the physical environment. As an outreach center of the School of Architecture, UACDC is developing a repertoire of design methodologies applicable to community development issues in
Arkansas, with currency at the national level. UACDC design solutions introduce a multiple bottom line, integrating socia and environmental measures into economic development. Integrative design solutions add long-term value and offer collateral benefits related to sustained economic capacity, enhanced ecologies, and improved public health; the foundations of creative development.

UACDC is focused on developing models for the everyday public realm, working between the bottom-up activism of grassroots organization and the top-down metrics of highly structured market forces and government agencies. UACDC is developing a longitudinal repertoire of place building design models in watershed planning, green street design, big box urbanism, low-impact residential planning, and transit-oriented development. Through work with communities, government agencies, private developers, and cor-

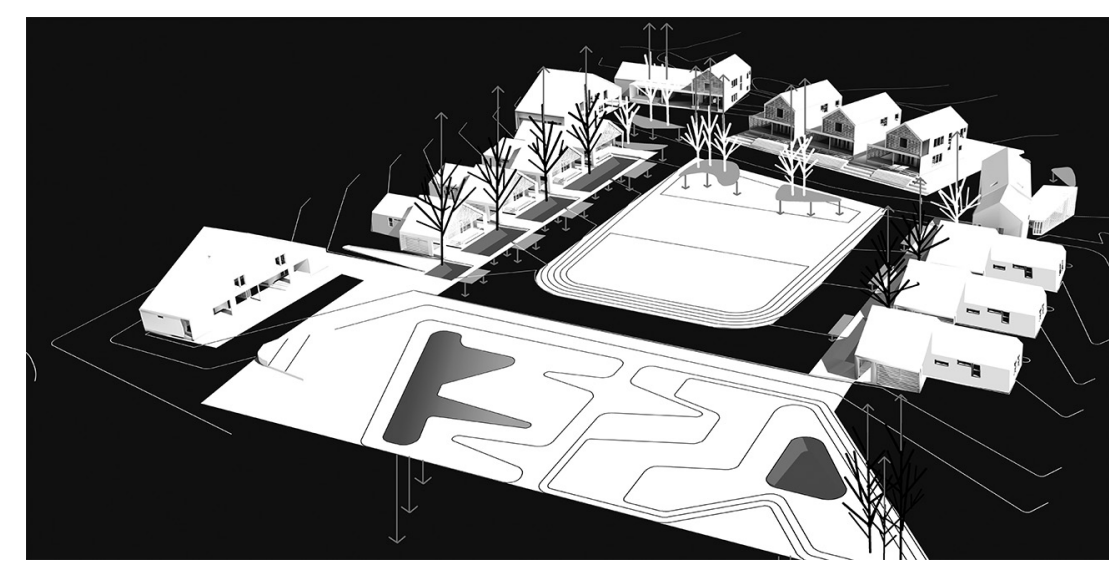

porations, UACDC's projects investigate the modularity of the environment, emphasizing infrastructural components' fit with one another.

Solving for place, or the everyday, provokes inquiries different from the discipline's most visible design tradition, the heroic. The heroic tradition celebrates signature projects, catalyzing influence, resources, and attention for designers and those who commission design. While the heroic tradition provides less than five percent of al that is built, it galvanizes the public's awareness of architecture and thus holds an important role in the ecology of the profession. The Renaissance architect heralds the heroic project, that moment when the designer distinguishes the built environment-an outcome of discrete thinking. In his latest book on the everyday environment and architecture, Palladio's Children, N.J. Habraken writes: ...labeling an architecture "Palladian" was an act of supreme significance. It distinguished the designer from the indissoluble unity of environmental form and culture that had until then brought forth buildings and entire urban fields, embodying skills and knowledge. From Palladio on, architecture has been identified with individual architects. Everything else-the entirety of the ordinary built field where form, inhabitant and maker are functionally integrated and semanticallyjoined-has remained obscure or self-evident. This has inevitably led to the emancipation-and the isolation-ofan entire professional culture from the integrated field of form and people.

As important as the heroic tradition has become so too is the profession's commitment to the "ordinary built field." Design achievement here involves attention to the civilizing of infrastructure, 

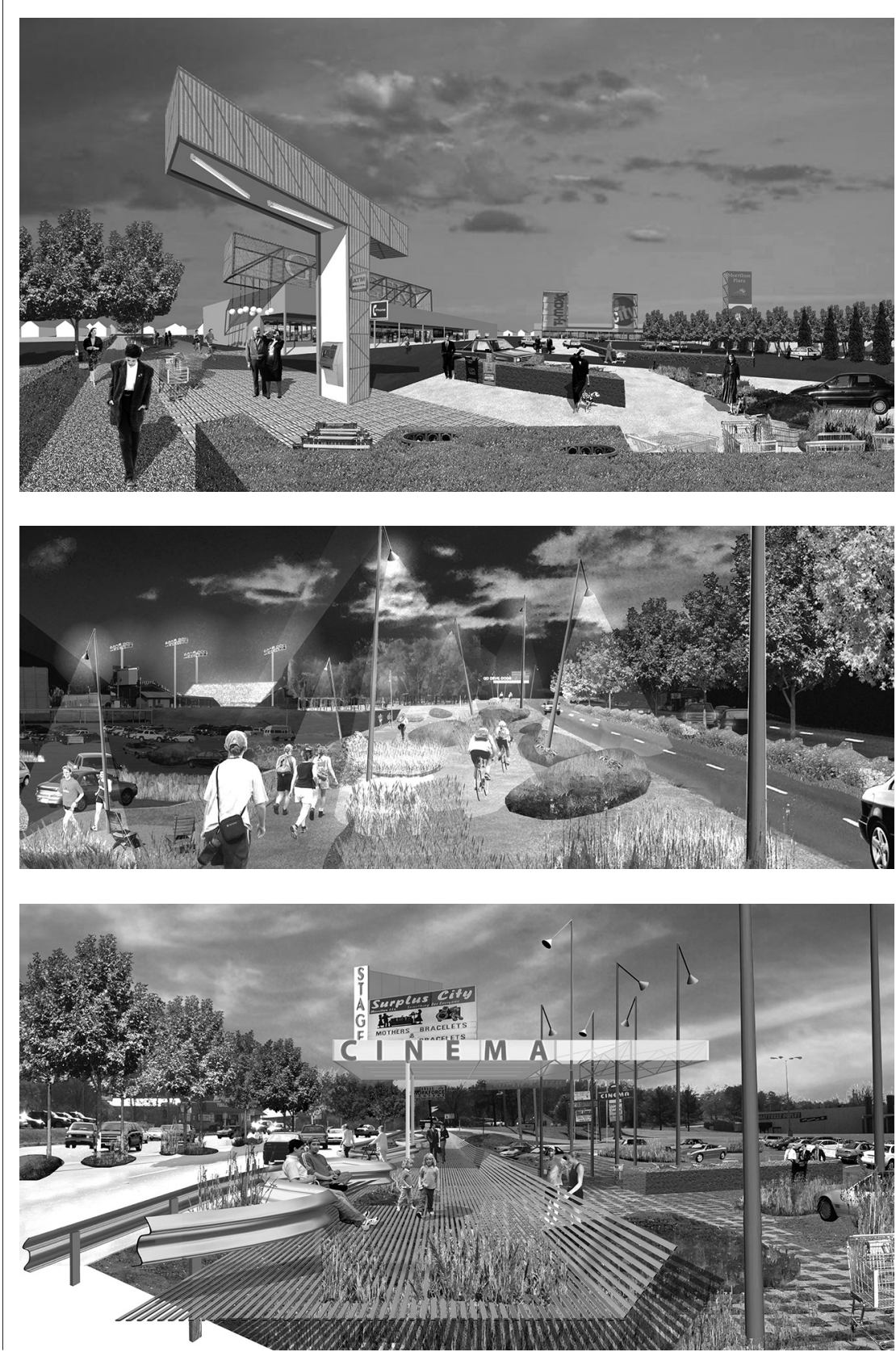

and a large category of miscellaneous development without an apparent architectural pedigree. Such work is distinguished by its engagement of insight from a cross-section of disciplinary and epistemological realms, from expert knowledge to vernacular wisdom. Yet, design culture's foray into the ordinary polarizes the conversation between two discursive anchors: 1) it erroneously claims authorship of historic fabrics, assuming quality to be a product of discrete thinking rather than of various delivery systems facilitated by pattern languages, or 2 ) cedes too much credit to participatory design, featuring the consumer rather than those who actually establish building protocols (contractors, public works departments, utilities, finance industry, developers, building professions). Though lacking a pedigree, the ordinary is no less designed-if not more-as it supports environmental configurations of far greater complexity than the discrete project.

\section{Beyond Aesthetics to \\ Metrics and Tools}

UACDC models begin with diagrammatic tools, like type, matrix, transect, map, and table to sort and sequence environmental resources. These resources not only constitute materia palettes and organizational strategies for developing fabrics, but also entai recombinant design methodologies. Recombinant design integrates metrics from ecology, engineering, architecture, and social policy in new formations not possible in their respective parent organizations. Different from the project parti or sketch, which formally consolidates design thinking towards a discrete end, recombinant design tools generate context-producing approaches with interdisciplinary metrics awaiting any number of formal considerations. Such cross-over combinations of environmental resources intensify feedback and responsive ness, enlarging possibilities within the ordinary built field. In her book, Organization Space: Landscapes, Houses, and Highways in America, which chronicles a lesser known tradition of recombinant thinking in progressive 20th century environmental design, Keller Easterling observes:

...while architects may be accustomed to resolving spaces according to aesthetic or geometric principles, some of the most common and powerful means of altering space might be best described as simply organizational expressions of spatial arrangements. The generic specifications for assembling offices, airports, highways, or other kinds offranchises are explicitly calibrated according to protocols for timing and interactivity, privileging not the formal, morphological attributes of building, but rather a repertoire of operatives affected by time, patterns of connectivity, and changing protocols of multiple components. These generic formats are processes and active organizations with powerful spatial consequences. 
Generic formats expressing the command-and-control infrastructure of official development culture resist robust local planning possibilities in the ordinary built field. Highway departments beholden to monolithic engineering protocols lack contextsensitivity in their administration of the largest classification of public space-the street. Witness their transportation manuals, which refer to trees as FHOs, "fixed and hazardous objects." The second largest area classification of public interest-riparian corridors and floodways-is managed under similar criteria, resulting in channelized infrastructure akin to sewers. Merchant builders commodify housing through subdivision development practices that resemble industrialized farming. The instrumentality of franchise culture has largely determined commercial development, once the vector of a vita public realm. Zoning, based on singleuse classifications, institutionalizes the absence of creative development, while the finance and mortgage industries underwrite this homogenization to ensure market fungibility.

Though the design professions hold little consequence in these official cultures, there are mounting pressures to enlist design thinking in creating the ordinary built field. Recently, public interests led by public health organizations (of course!) have invited the design professions to address intractable planning problems related to affordability, health, and mobility. Are the design professions ready to leverage their potential social agency, and have we followed up with models to satisfy multiple bottom lines?

\section{Some Recombinant \\ Design Models}

Over the last two years UACDC has focused on the development of placebased models in the course of solving for individual projects. The aim is to create a lexicon of progressive planning practices from the following approaches.

\section{Watershed-Based Urbanism: Hydrology as a Platform for Community Development}

The planning goal is to restore the ecological functioning of riparian systems while leveraging development quality in adjacent land uses. Well functioning streams provide urban infrastructural services related to flood control, storm water treatment (keeping in mind that the first hour of urban rainfall runoff has a pollution index much greater than that of raw sewage), and erosion control, in addition to fourteen other ecological services. Two major hydrological concerns in most communities are flooding and storm water infiltration of sewer systems during storms. The first problem can cause extensive property loss while the latter constitutes fine-inducing violations of the Clean Water Act. Ecologically-based design dampens excessive stream flow through reclamation of lost urban floodplains and formation of the
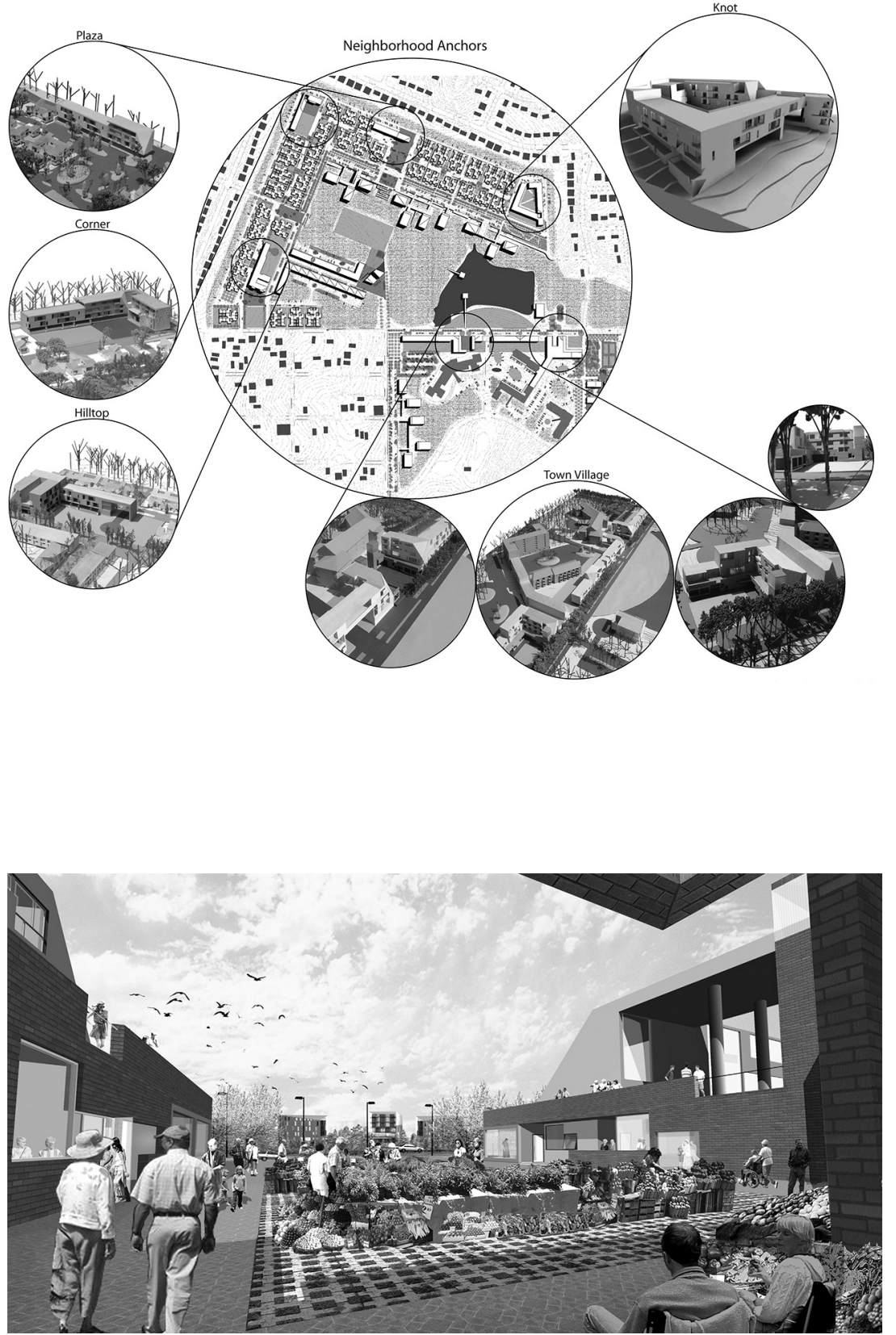

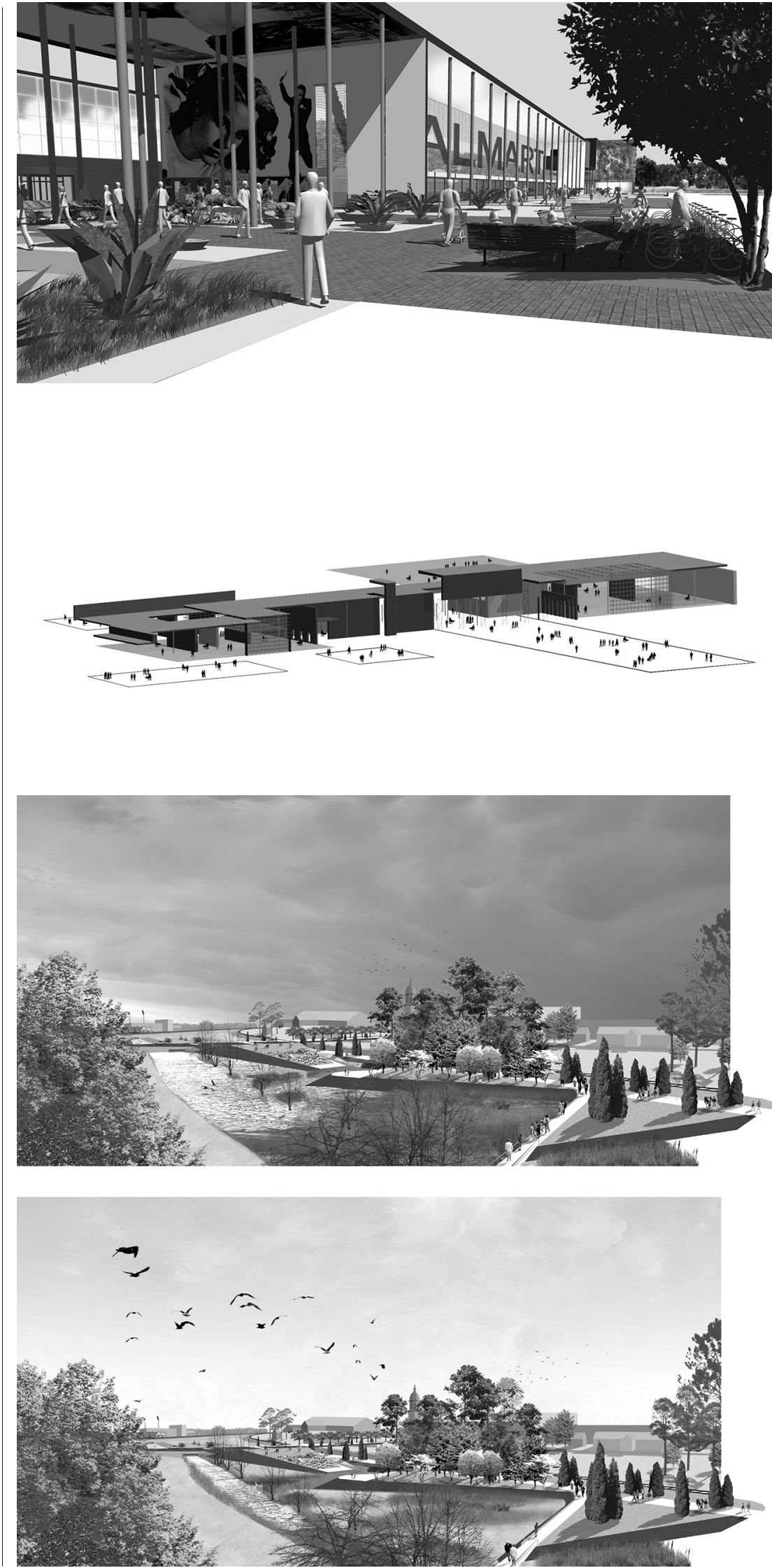

riffle-pool-glide algorithm present in healthy stream organization. These corrective measures are supplemented by vegetation of riparian edges, return of stream sinuosity, and strategic bank armoring to prevent excessive erosion and sediment transport. Metabolic improvements to the riparian corridor generate an extended family of urban conditions. Floodplains become parks; newly planted and armored riparian edges form recreation corridors; and storm water gardens organize new synthetic street and parking landscapes as hydrological processes imprint their patterns onto the urban field.

\section{Shared Streets and}

\section{Highway Ecologies}

Contemporary traffic management maximizes vehicular flow and speed, engineering environmental, social, and architectural functions out of the street. Two recombinant models for streets reinstate multiple functions within the right-of-way related to assembly, pedestrian and bicyclist circulation, landscape systems, and storm water facilities. The shared street, a derivative of the Dutch woonerf, serves as a neighborhood planning system integrating house frontages, pedestrian plazas, green parking systems, and storm water gardens with traffic throughways. This traffic-calming ecology imprints a unique neighborhood landscape without the use of speed bumps, humps, signs, and other ineffective traffic regulation devices, allowing the pedestrian to claim the street with the same authority as the motorist.

The Highway Ecology Matrix is an index of the generic things and systems typically found in a highway corridor. The horizontal variation in matrix components, indicated by "Increasing Service," illustrate their successive phases of development from the most elemental form to context-producing systems. The matrix functions as a community participation instrument, facilitating unexpected combinations to achieve context-sensitive infrastructure design.

\section{Low-Impact}

Neighborhood Development and Affordable Housing

Affordability is achieved through conservation planning that pools otherwise private resources to create a shared neighborhood landscape. Keeping in mind Wendell Berry's adage that a "good solution in one pattern preserves the integrity of the pattern that contains it," four neighborhood planning fabrics are integrally developed within a "Living Transect": 1) open space, 2) green street, 3) hydrology, and 4) porch-house typology. Ecological-based solutions for storm water runoff treatment, conveyance, and recharge are substituted for costly and ineffective "pipe and pond" solutions. Green streets, consisting of bioswale corridors, infiltration trenches, storm water gardens, and sediment filter strips eliminate the need for curbs and gutters, leaders, traps, and other civil catchment infrastructure-"parks, not pipes." Recombining ecological performance with civil infrastructure expresses a place-based neighborhood aesthetic and regional watershed solution. This amenity-rich neighborhood is a cost-effective way to create home value and provide public services at the scale of a block.

\section{Finding the Social in \\ Big Box Urbanism}

How does community-minded development occur in places without models of traditional urbanism - where logistics have substituted an urbanism of its own? Big box parcels are implicated in a complex urbanism governed by land use regulations, transportation configurations, public utility codes, vehicular requirements, shopping patterns, and franchise protocols-a logistics landscape. The goal is to develop community-based design solutions responsive to this recent form of urbanism. Employing analytical methods from the ecological sci- 
ences, a site transect with five ecotones was developed for a typical property. Ecotones describing edge relation ships between public street, outer ring parking, inner ring parking, building frontage, store "decompression" zone, and checkouts provided a vocabulary to engage non-urban development protocols. An urban ecology of zones, regulations, and use procedures is complemented by the introduction of familiar community-building elements like porches, arcades, or courtyards that challenge the non-place formats of franchising.

\section{Arboreal Urbanism}

As a catalyst to shape growth, can landscapes seed an early stage urbanism without buildings? The project proposes that urban reforestation may begin with the tree as an irreducible unit to create large-scale orders. Because the garden's fundamental logic is defined by algorithmic protocols (cellular automata and Fibonacci proportions), room configurations can change without compromising the garden's underlying coherence. Indeed, planning relies on ecological successional development of ever-greater biological complexity. In a process known as emergence, tree arrangements morph from the managed effect of one species to produce self-organizing species clusters, creating diverse "climax" communities. Akin to a pixilated landscape, the garden is an emergent system characterized by planting and thinning algorithms, yet, employs identifiable arboreal spaces like alleés, bosques, hammocks, and groves to form outdoor rooms. Landscape space displaces architecture as the generative force in the contemporary expanded urban field.

\section{Beyond Philanthropy}

Mitigating market and planning failures is an imperative and certainly can be uplifting. However, the essence of a profession's humanitarianism is in its capacity to progressively determine organization culture. A profession is not the sum of its individual practices.
Just as medical practices do not solve for public health problems nor provide research solutions for say, cancer; the source of humanitarianism in a profession is its social capital. I will not forget enthusiastically showing a talented planning colleague from Sweden the first book on Rural Studio's widely celebrated design/build work in Alabama. An excellent designer and thoughtful scholar, he was scandalized by the social conditions that allowed such impoverishment in the first place, not allowing a moment of celebration to acknowledge accomplished design Perhaps he believed that congratulations for downstream solutions, no matter how noble their mitigation of adverse circumstances, poses a distraction from the upstream work that awaits design if it aims to remain a profession.

\section{UACDC Design Staff}

Stephen Luoni

Aaron Gabriel

Jeffrey Huber

John McWilliams

James Meyer
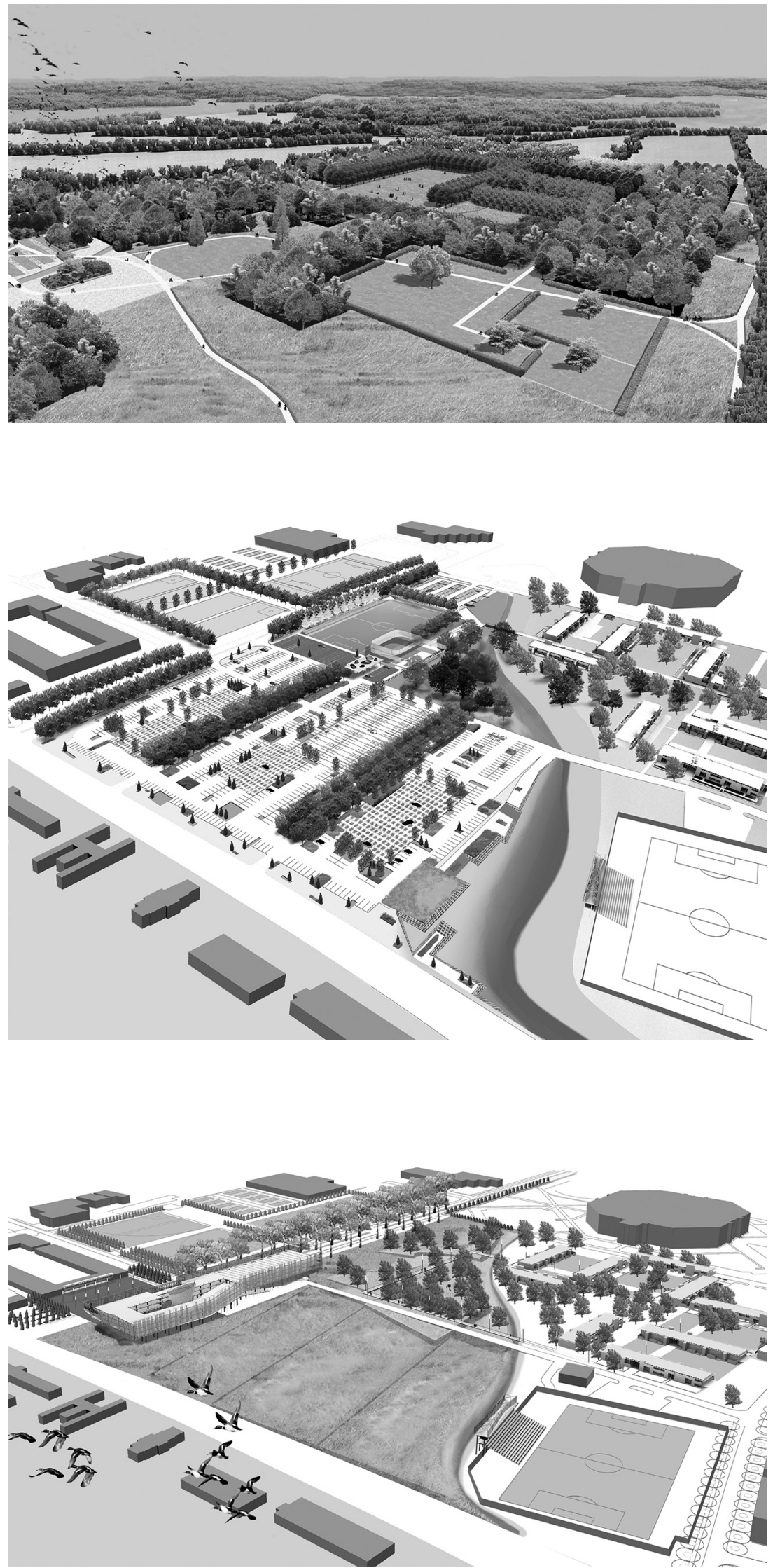